DOI: $10.34185 / 1991-7848.2019 .01 .03$

УДК 621.891

Т.О. Васильченко, І.А. Шевченко, Ю.Г. Кобрін, О.М. Гречаний

\title{
ТЕОРЕТИЧНІ ДОСЛІДЖЕННЯ ПРОЦЕСУ ДРОБЛЕННЯ КРИХКИХ МАТЕРІАЛІВ В МОЛОТКОВИХ ДРОБАРКАХ
}

\begin{abstract}
Ефективне проведення ударно-стираючого дроблення пов'язано 3 переносом енерговитрат в бік безпосереднього здрібнення. Завдання роботи - з'ясувати закономірності енерговитрат процесу дроблення в залежності від співвідношення впливу способів ударного руйнування та руйнування тертям, а також зміни характеристик міцності подрібнювального матеріалу при аналізі роботи молоткової дробарки. Розглядається дроблення твердих й крихких матеріалів шляхом руйнування їх початкової структури ударом і стиранням в дробарках з шарнірно підвішеними молотками та три стадії дроблення. Проведено теоретичні дослідження що до визначення енергопотреб необхідних для проведення ударно-стираючого дроблення в залежності від співвідношення впливу способів ударного руйнування та руйнування тертям. Встановлено залежність енерговитрат процесу дроблення від характеристик матеріалу та способу дроблення рівняння (16), яке дає можливість порівняти долю впливу двох видів руйнівного навантаження: ударного руйнування та руйнування тертям для процесів з різним рівнем дисперсності подрібненого матеріалу. Дроблення ударом з мінімізацією тертя частинок матеріалу по робочим органам молоткової дробарки значно зменшує енерговитрати. Це дає можливість застосувати раціональний спосіб дроблення.Результати чисельного розрахунку можуть бути застосовані при виборі раціональних геометричних параметрів молоткових дробарок. Отримані залежністі енерговитрат процесу дроблення від характеристик матеріалу та способу дроблення які дають можливість застосувати раціональний спосіб дроблення в молоткових дробарках.
\end{abstract}

Ключові слова: дроблення, стирання, розколювання, сколювання, міцність.

\section{Вступ}

В багатьох галузях промисловості особливе місце займають процеси подрібнення матеріалів, як найбільш важливі та енергоємні. Встановлено, що на операції дроблення кожного року витрачається не менш 5\% всієї виробленої в світі енергії. Така велика доля в загальному енергетичному балансі підкреслює місце і важливість процесів дроблення в життєдіяльності людини [1]. Для дроблення крихких і м’яких матеріалів: кам'яного вугілля, крейди, вапняку, коксу та ін. застосовують молоткові дробарки.

\section{Аналіз досягнень}

Дроблення твердих і крихких матеріалів до часток бажаного розміру доцільно здійснювати шляхом руйнування їх початкової структури різними видами 
деформації; як правило, роздавлюванням, ударом і розколюванням, та різними поєднаннями цих способів.

В основу молоткових дробарок з шарнірно підвішеними молотками закладено принцип руйнування крихких кускових геоматеріалів багатократним ударом i стиранням [2,3]. Руйнування ударом i стиранням характеризується високою універсальністю як по відношенню можливості дроблення різних видів матеріалів, так і по відношенню ступеня їх дроблення.

До робочих органів молоткових дробарок відносяться молотки, решітки (колосникові) і деки, відбійні плити, які утворюють дробильну камеру.

В молоткових дробарках можна виділити три стадії дроблення:

1. розколювання - удар молотків по матеріалу (для неї характерним є удар по рухомій масі матеріалу стадія, що призводить переважно до розколювання);

2. сколювання - удар матеріалу від відбійну плиту (для якої характерним є удар о нерухому масу машини, що призводить переважно до сколювання);

3. стирання - стирання матеріалу о відбійну плиту і колосникову решітку, а також при зіткненні частинок матеріалу між собою.

При такій схемі здрібнення ударна дія є основним компонентом.

Дроблення частинок матеріалу проходить поетапно. Ударний вплив призводить до розколювання частинки матеріалу щонайменше на дві частини. Кожен з уламків обтирається за рахунок сил тертя. Частина матеріалу, що утворюється за рахунок стирання, вважається дуже дисперсною і тому не приймає участі у подальшому процесі дроблення. Кожна з частинок, отриманих після розколювання початкової частинки та обтирання, знову розколюється щонайменше на дві частинки, кожна 3 котрих обтирається. Таким чином процес триває доки частинки матеріалу не зменшяться до потрібного розміру.

В молоткових дробарках частинки матеріалу руйнується за рахунок їх розколювання внаслідок ударного впливу (ударом вльоті) та стирання. Причому, більша частина витрачається саме на дроблення матеріалу за рахунок стирання, а не удару, що приводить до надлишкового збільшення питомих енерговитрат на одиницю готового продукту. Так, наприклад, за даними С.П. Джинджихадзе, в молотковій дробарці при лінійній швидкості молотків 110 м/с на дроблення ударом витрачається тільки 16,9\% від всієї енергії що підводиться, а на дроблення стиранням - 83,1\% [4].

\section{Постановка завдання}

Ефективне проведення ударно-стираючого дроблення пов'язано з переносом енерговитрат в бік безпосереднього здрібнення. Завдання роботи - з'ясувати закономірності енерговитрат процесу дроблення в залежності від співвідношення впливу способів ударного руйнування та руйнування тертям, а також зміни характеристик міцності подрібнювального матеріалу при аналізі роботи молоткової дробарки. 


\section{Головна частина досліджень}

Для руйнування частинок матеріалу витрачається певна кількість енергії, що залежить від міцності подрібнювального матеріалу. Згідно зі статистичною теорією міцності [1], дефекти в будові твердого тіла розподілені стохастично за об'ємом; тобто зменшення розмірів часток приводить до зменшення числа дефектів. Залежність міцності твердих тіл від лінійних розмірів є масштабним фактором [5].

В молоткових дробарках матеріал руйнується за рахунок розколювання його частинок внаслідок ударного впливу та стирання.

Корисна робота, що витрачається на подрібнення складається з роботи удару $A_{y д} \mathrm{i}$ роботи тертя $A_{\text {mер}}$ :

$$
A=A_{\text {уд }}+A_{\text {mер }} .
$$

Співвідношення цих двох стадій процесу руйнування передумовлює сумарні i питомі витрати енергії на весь процес. Для молоткових дробарок вигідно забезпечити відносно велику величину першої стадії.

Руйнування ударом (розколювання) виникає, коли енергія пружної деформації, що накопичена тілом, переходить в поверхневу енергію утворення нової поверхні:

$$
A_{\text {yd }}=\frac{\sigma^{2} V}{2 E}=\frac{\sigma^{2} k d^{3}}{2 E},
$$

де $\sigma$ - границя міцності на стискання частинки матеріалу, Па/м² ;

$V$ - об'єм частинки матеріалу, $\mathrm{m}^{3}$;

$d$ - розмір частинки матеріалу (діаметр сфери описаної навколо багатогранника, до форми якого прямує форма частки матеріалу), м;

$k$ - коефіцієнт форми;

$E$ - модуль пружності матеріалу (модуль Юнга), Па/м².

Якщо ввести параметр $p$, який характеризує долю енергії, що приходиться на подрібнення ударом, то енергії тертя відповідає доля в (1-p).

Міцність матеріалу починає значно збільшуватись 3 досягненням частинки певного критичного розміру $-d_{\text {кр }}$, який визначається окремо для кожного матеріалу [3]. Тобто процес подрібнення внаслідок розколювання під впливом ударного навантаження можна поділити на два етапи: дроблення до критичного розміру частинок і дроблення частинок до розміру, меншого за критичний. В першому етапі процесу дроблення проявом масштабного ефекту можна знехтувати через незначне його проявлення та прийняти значення границі міцності матеріалу на стискання сталим. Воно має дорівнювати практичному значенню границі міцності для даного конкретного матеріалу - $\sigma_{n p}$. Якщо перша частина процесу дроблення (від початкового розміру $d$ до критичного розміру $d_{k p}$ ) реалізується за $n_{1}$ етапів, то енергія, необхідна для руйнування ударом однієї частки матеріалу дорівнює:

$$
A_{\text {yə.1 }}=\frac{\sigma_{n p}^{2} k d^{3}}{2 E} \sum_{i=0}^{n_{1}} p^{i}
$$


В другому етапі процесу дроблення границя міцності починає зростати, тобто її значення буде залежати від розміру частинки (ступеню дроблення). Представимо прояв масштабного фактору починаючи від розміру частки $d_{k p}$ у вигляді експоненційної залежності границі міцності від етапу подрібнення [5]. Таким чином границя міцності буде асимптотичне прямувати від практичного значення до теоретичного:

$$
\sigma_{i}=\sigma_{n p}+\sigma_{T}+\left(1-e^{-\alpha t}\right),
$$

де $\sigma_{i}$ - границя міцності на стискання на і-му етапі дроблення, Па/ $\mathrm{m}^{2}$;

$\sigma_{n p}$ - практичне значення границі міцності на стискання для даного матеріалу для частинок більших за розміром, ніж $d_{k p}, \Pi а / \mathrm{m}^{2}$;

$\sigma_{T}$ - теоретичне значення границі міцності матеріалу на стискання, що визначається за рівнянням Орована-Келлі, Па/м²;

$\alpha$ - коефіцієнт масштабного ефекту, який визначається емпірично для кожного конкретного матеріалу при заданому значенні $p$ для даного процесу дроблення;

i - етап дроблення.

Для другого етапу процесу значення енергії, що витрачається на дроблення однієї частинки матеріалу від початкового розміру $d_{k p}$ до заданого можна визначити наступним рівнянням:

$$
A_{\text {уд.2 }}=\frac{k d_{k p}^{3}}{2 E} \sum_{i=0}^{n_{2}}\left[p^{i}\left(\sigma_{n p}+\sigma_{T}\left(1-e^{-\alpha t}\right)\right)^{2}\right],
$$

де $n_{2}$ - кількість етапів дроблення другої частини процесу.

Руйнування тертям - обтирання виникає за рахунок накопичення руйнівних напружень в нескінченно тонких поверхневих шарах часток матеріалу в результаті чого видаляється матеріал у вигляді надтонкої фракції. Оскільки процес обтирання протікає поетапно 3 накопиченням руйнівного напруження в надтонкому шарі матеріалу, то границя міцності для цього процесу прямує до теоретичного значення за рахунок малих об'ємів накопичення та руйнування. Це зумовлено мінімально можливою кількістю дефектів структури для нескінченно малого об'єму матеріалу.

Робота сил тертя, яка витрачається на обтирання (1-p) долі матеріалу частинки початковим розміром $d$ дорівнює для першого і другого етапів процесу дроблення відповідно:

$$
\begin{aligned}
& A_{\text {mep } .1}=\frac{\sigma_{T}^{2} k d^{3}}{2 E}\left(1-p^{n_{1}}\right), \\
& A_{\text {mep. } 2}=\frac{\sigma_{T}^{2} k d_{k p}^{3}}{2 E}\left(1-p^{n_{2}}\right) .
\end{aligned}
$$

Вираз, що визначає роботу, яка витрачається на дроблення частинки матеріалу від початкового розміру $d$ до розміру початку прояву масштабного фактору $d_{k p}$, визначається сумою рівнянь (3) та (6): 


$$
A_{1}=\frac{k d^{3}}{2 E}\left(\sigma_{n p}^{2} \sum_{i=0}^{n_{1}} p^{i}+\sigma_{T}^{2}\left(1-p^{n_{1}}\right)\right) .
$$

Після додавання рівнянь (5) та (7) отримаємо вираз для визначення роботи, яка витрачається на дроблення частинки матеріалу від розміру початку прояву масштабного фактору $d_{k p}$ до кінцевого розміру $d_{k}$ в $n_{2}$ етапів:

$$
A_{2}=\frac{k d_{k p}^{3}}{2 E}\left(\sigma_{n p}^{2} \sum_{i=0}^{n_{2}} p^{i}\left(\sigma_{n p}+\sigma_{T}\left(1-e^{-\alpha t}\right)\right)^{2}+\sigma_{T}^{2}\left(1-p^{n 2}\right)\right) .
$$

У випадку розглядання дроблення частинки від початкового розміру $d$, більшого за $d_{k p}$ до кінцевого розміру $d_{k}$, меншого за $d_{k p}$, робота, яка витрачається на дроблення виражається у вигляді суми рівнянь (8) та (9). Необхідно враховувати той факт, що на початку другої частини в процесі дроблення приймає участь $a^{n 1}$ частинок розміром $d_{k p}$, які було утворено в результаті дроблення початкової частинки за $n_{1}$ етапів. Приймаємо мінімальне значення кількість частинок, що утворюються в результаті розколювання під впливом ударного навантаження $a=2$. Звідси:

$$
A=\frac{k d^{3}}{2 E}\left(\sigma_{n p}^{2} \sum_{i=0}^{n_{1}} p^{i}+\sigma_{T}^{2}\left(1-p^{n_{1}}\right)\right)+2^{n_{1}} \frac{k d_{k p}^{3}}{2 E}\left(\sum_{i=0}^{n_{2}}\left(p^{i}\left(\sigma_{n p}+\sigma_{T}\left(1-e^{-\alpha t}\right)\right)^{2}\right)+\sigma_{T}^{2}\left(1-p^{n_{2}}\right)\right)
$$

Вираз (10) показує залежність роботи, витраченої на дроблення однієї частинки, від етапу дроблення. Для того, щоб сформулювати аналогічну залежність для дроблення матеріалу масою $m_{m}$, треба вираз (10) помножити на кількість частинок $N$, що міститься в матеріалі масою $m_{м}$ :

$$
N=\frac{m_{M}}{m_{u}}=\frac{m_{M}}{k d^{3} \rho},
$$

де $\quad m_{м}$ - маса матеріалу, що підлягає дроблення, кг;

$m_{\text {ч }}$ маса однієї початкової частинки матеріалу, що підлягає подрібненню, кг;

$\rho$ - густина матеріалу, кг $/ \mathrm{M}^{3}$.

Тоді енергія, яка витрачається на дроблення :

$$
A=\frac{m_{M}}{2 E \rho}\left(\sigma_{n p}^{2} \sum_{i=0}^{n_{1}} p^{i}+\sigma_{T}^{2}\left(1-p^{n_{1}}\right)\right)+2^{n_{1}} \frac{d_{k p}^{3}}{2 E}\left(\sum_{i=0}^{n_{2}}\left(p^{i}\left(\sigma_{n p}+\sigma_{T}\left(1-e^{-\alpha t}\right)\right)^{2}\right)+\sigma_{T}^{2}\left(1-p^{n_{2}}\right)\right) .
$$

Для того, щоб виразити значення енергії, яка витрачається на дроблення від геометричних розмірів часток матеріалу, що дробляться, визначимо значення кількості етапів дроблення у кожній частині цього процесу. Максимальна ступень дроблення матеріалу $u$ дорівнює відношенню початкового розміру частинки до кінцевого. 3 кожним етапом кожна частинка розколюється на $a$ шматків. Звідси

$$
a^{n}=\frac{d^{3}}{d_{k}^{3}}=u^{3} .
$$

Прийнявши мінімальне значення $a=2$, визначимо кількість етапів, необхідних для отримання певного розміру частинки матеріалу, що дробиться:

$$
n=\frac{3 \lg u}{\lg 2} \approx 10 \lg \frac{d}{d_{k}} .
$$


3 цього рівняння можна виразити кількості етапів першої та другої частин процесу дроблення.

$$
n_{1}=10 \lg \frac{d}{d_{k p}} ; \quad n_{2}=10 \lg \frac{d_{\kappa p}}{d_{k}} .
$$

Таким чином, залежність роботи, що витрачається на дроблення маси матеріалу $m_{m}$ комбінованим способом удару та стирання від початкового та кінцевого розміру частинок, характеристик матеріалу (початкова практична границя міцності, розмір частинки початку прояву масштабного фактору, коефіцієнт масштабного фактору, теоретична границя міцності даного матеріалу, параметр характеру процесу дроблення) визначається шляхом підстановки виразів (15) до рівняння (12) та оскільки при дроблені прояв масштабного фактору незначний, його впливом можна знехтувати. Отже, для опису необхідної енергії для дроблення достатньо розглядати першу частину процесу. Тоді вираз для визначення енергопотреб має вигляд:

$$
A=\frac{m_{M}}{2 E \rho}\left(\sigma_{n p}^{2} \sum_{i=0}^{10 \lg \frac{d}{d_{k p}}} p^{i}+\sigma_{T}^{2}\left(1-p^{10 \lg \frac{d}{d_{k p}}}\right)\right) .
$$

\section{Висновки}

Встановлено залежність енерговитрат процесу дроблення від характеристик матеріалу та способу дроблення - рівняння (16), яке дає можливість порівняти долю впливу двох видів руйнівного навантаження: ударного руйнування та руйнування тертям для процесів 3 різним рівнем дисперсності подрібненого матеріалу. Дроблення ударом з мінімізацією тертя частинок матеріалу по робочим органам молоткової дробарки значно зменшує енерговитрати. Це дає можливість застосувати раціональний спосіб дроблення.

Результати чисельного розрахунку можуть бути застосовані при виборі раціональних геометричних параметрів молоткових дробарок.

\section{ЛITEPATУРА}

1. Сиденко П. М. Измельчение в химической промышленности / П. М. Сиденко. Москва: Химия, 1977. - 305 с.

2. Бонд Ф. С. Законы дробления / Ф. С. Бонд. // Стройиздат. - 1966. - С. 195-208.

3. Андреев С. Е. Дробление, измельчение и грохочение полезных ископаемых / С. Е. Андреев, В. А. Перов, В. В. Зверевич. - Москва: Недра, 1980. - 415 с.

4. Джинджихадзе С. П. Исследование энергоемкости процесса дробления фуражного зерна в молотковых дробилках : автореф. дис. на здобуття наук. ступеня канд. техн. наук / Джинджихадзе С. П. - Тбилиси, 1965. - 35 с. 
5. Кузнецова М. М. До питання оптимізації технологічного процесу подрібнення в будівництві / М. М. Кузнецова, А. Г. Приймаков. // Науковий вісник будівництва. ХДТУБА. - 2010. - №58. - С. 133-141.

6. Кузнецова М. М. Вплив способу подрібнення на енерговитрати процесу / М. М. Кузнецова, В. Є. Ведь. // Інтегровані технології та енергозбереження. ХДТУБА. 2014. - №2. - C. 18-22.

7. Качанов Л. М. Основы механики разрушения / Л. М. Качанов. - Москва: Наука, 1974. -312 c.

8. Васильченко Т. О. Аналіз руйнування крихких матеріалів ударом / Т. О. Васильченко, І. А. Шевченко, Ю. Г. Кобрін. // Наукові праці Запорізької державної інженерної академії. - 2017. - №2. - С. 116-122.

\section{REFERENCES}

1. Sidenko P. M. Izmelchenie v himicheskoy promyishlennosti / P. M. Sidenko. - Moskva: Himiya, 1977. - $305 \mathrm{~s}$.

2. Bond F. S. Zakonyi drobleniya / F. S. Bond. // Stroyizdat. - 1966. - S. 195-208

3. Andreev S. E. Droblenie, izmelchenie i grohochenie poleznyih iskopaemyih / S. E. Andreev, V. A. Perov, V. V. Zverevich. - Moskva: Nedra, 1980. - 415 s.

4. Dzhindzhihadze S. P. Issledovanie energoemkosti protsessa drobleniya furazhnogo zerna v molotkovyih drobilkah : avtoref. dis. na zdobuttya nauk. stupenya kand. tehn. nauk / Dzhindzhihadze S. P. - Tbilisi, 1965. - 35 s.

5. Kuznetsova M. M. Do pytannia optymizatsii tekhnolohichnoho protsesu podribnennia v budivnytstvi / M. M. Kuznetsova, A. H. Pryimakov. // Naukovyi visnyk budivnytstva. 2010. - №58. - S. 133-141.

6. Kuznetsova M. M. Vplyv sposobu podribnennia na enerhovytraty protsesu / M. M. Kuznetsova, V. Ye. Ved. // Intehrovani tekhnolohii ta enerhozberezhennia. KhDTUBA. - 2014. - №2. - S. 18-22.

7. Kachanov L. M. Osnovyi mehaniki razrusheniya / L. M. Kachanov. - Moskva: Nauka, 1974. - $312 \mathrm{~s}$.

8. Vasylchenko T. O. Analiz ruinuvannia krykhkykh materialiv udarom / T. O. Vasylchenko, I. A. Shevchenko, Yu. H. Kobrin. // Naukovi pratsi Zaporizkoi derzhavnoi inzhenernoi akademii. - 2017. - №2. - S. 116-122.

Received 11.01.19

\section{THEORETICAL STUDIES OF THE PROCESS OF FRAGMENTATION OF FRAGILE MATERIALS IN HAMMER MILLS}

A large share in the overall energy balance emphasizes the place and importance of crushing processes in human life, therefore crushing hard and brittle materials is considered by destroying their original structure by impact and erasing crushers with hinged hammers, namely: splitting - hitting hammers on the material (for it the impact on the moving mass of the material stage is characteristic, it leads mainly to splitting); spalling - the impact of material from the baffle plate (which is characterized by a blow to the motionless mass of 
the machine, which leads mainly to spalling); erasing - erasing the material in the baffle plate and grate, as well as in the collision of material particles with each other.

In hammer mills, the material particles are destroyed due to their splitting as a result of impact (ingress) and abrasion.

The effective conduct of impact-washing crushing is associated with the transfer of energy consumption in the direction of direct grinding. Therefore, the task of the work was to find out the laws of the energy consumption of the crushing process depending on the ratio of the impact of impact damage and friction destruction methods, as well as changes in the crushing material strength when analyzing the operation of a hammer crusher.

The useful work spent on crushing consists of the work of the impact Ауд and the work of friction Атер, namely the ratio of these two stages of the destruction process is a prerequisite - the total and specific energy consumption for the whole process.

The destruction by impact (splitting) occurs when the energy of elastic deformation, accumulated by the body, goes into the surface energy of the formation of a new surface.

Friction - wiping destruction occurs due to accumulation of destructive stresses in infinitely thin surface layers of material particles, as a result of which material is removed in the form of a superfine fraction. Since the wiping process proceeds in stages with the accumulation of destructive stress in the ultrathin layer of material, the ultimate strength for this process tends to the theoretical value due to small volumes of accumulation and destruction. This is due to the minimum possible number of structural defects for an infinitely small volume of material.

The paper presents the dependence for comparing the influence of two types of destructive load: impact destruction and destruction by friction for processes with different levels of dispersion of the material being crushed to enable the application of the crushing method.

Keywords: crushing, abrasion, splitting, scraping, strength.

Васильченко Тетяна Олександрівна - к.т.н., доцент кафедри «Металургійне обладнання», Запорізький національний університет.

Vasilchenko Tatyana Oleksandrivna - candidate of technical sciences, associate professor professor of department of metallurgical equipment, Zaporizhzhia national university.

Шевченко Ірина Артурівна - к.т.н., доцент кафедри «Металургійне обладнання», Запорізький національний університет.

Shevchenko Irene Arturivna - candidate of technical sciences, associate professor professor of department of metallurgical equipment, Zaporizhzhia national university.

Кобрін Юрій Григорович - апірант, Національна металургійна академія України.

Kobrin Yurii Hryhorovych - graduate student, National metallurgical academy of Ukraine.

Гречаний Олексій Миколайович - апірант, Національна металургійна академія України.

Hrechanyi Oleksii Mykolaiovych - graduate student, National Metallurgical Academy of Ukraine. 